\title{
ISOLAMENTO E IDENTIFICAČ̃̃O DE BACTÉRIAS PRESENTES NOS SOLOS DE COBERTURA UTILIZADOS NO CULTIVO DO COGUMELO Agaricus blazei MURRIL ${ }^{1}$
}

\author{
Isolation and identification of bacteria present in the casing layer utilized to the cultivation of \\ the mushroom Agaricus blazei Murril
}

\author{
Valdirene Aparecida da Silva ${ }^{2}$, Eustáquio Souza Dias ${ }^{3}$, Roberta Hilsdorf Piccoli do Vale ${ }^{4}$, \\ Romildo da Silva ${ }^{3}$, Grazielle Furtado Moreira ${ }^{5}$
}

\begin{abstract}
RESUMO
Este trabalho foi desenvolvido com o objetivo de isolar e identificar bactérias presentes nos solos utilizados como camada de cobertura do cultivo de Agaricus blazei Murril. Foi avaliada a eficiência da desinfestação com vapor d'água e formol nos solos de cobertura. $\mathrm{O}$ tratamento com formol apresentou maior redução no número de bactérias na terra de barranco (Latossolo Vermelho distroférrico) e solo de pastagens (Latossolo Amarelo distrófico), enquanto que no solo hidromórfico, oriundo de várzea (Gleissolo Melânico), nenhum dos tratamentos foi eficiente para reduzir a comunidade microbiana. Foram identificadas bactérias do gênero Pseudomonas, Salmonella, Enterobacter e Shigella, dentre outras, denotando que os tratamentos de desinfestação não eliminam bactérias potencialmente benéficas, mas também não eliminam bactérias potencialmente patogênicas. Além disso, os tratamentos de desinfestação também não afetaram a produtividade do cogumelo A. blazei nas condições testadas.
\end{abstract}

Termos para indexação: Agaricus blazei, cogumelo comestível, camada de cobertura, desinfestação.

\section{ABSTRACT}

The objective of this work was to quantify and to isolate the bacteria present in casing layer used for the cultivation of the Agaricus blazei Murril. It was evaluated the efficiency of the steam and formaldehyde disinfestation in the casing layer. The formaldehyde disinfestation showed a reduction of the bacteria population on the ravine soils (distroferric Red Latosol) and grazing land soil (distrofic Yellow Latosol), while in the hydromorphic soil coming from lowland (Melanic G]/leysol) none of the treatments used were efficient to reduce the bacteria population. Bacteria of the genera Pseudomonas, Salmonella, Enterobacter, Shigella, among others, were identified in all treatments analysed. It was observed that the disinfestation treatments did not eliminate neither potentially beneficial bacteria nor pathogenic bacteria. There was no significant effect of the disinfestation treatments on productivity of A. blazei mushroom. Moreover, the disinfestation treatments did not affect the productivity of the A. blazei in the studied conditions.

Index terms: Agaricus blazei, edible mushrooms, casing layer, disinfestation.

\section{(Recebido em 2 de junho de 2005 e aprovado em 1 de junho de 2006)}

\section{INTRODUÇÃo}

A espécie Agaricus blazei Murril, popularmente conhecida como "cogumelo-do-sol ${ }^{\circledR ”}$ é nativa do Brasil e foi identificada inicialmente no sul do Estado de São Paulo, na década de 60 (BRAGA et al., 1998). O cultivo comercial dessa espécie vem sendo intensificado devido ao seu valor nutricional e potencial terapêutico (KAWAGISHI et al., 1990; MIZUNO et al., 1990a,b).

Por ser uma espécie de cultivo recente no Brasil, a produção do cogumelo $A$. blazei ainda é praticada de forma empírica pela maioria dos produtores (BRAGA \& EIRA, 1999; BRAGA et al., 1998), com base na tecnologia de produção do "champignon de Paris" (Agaricus bisporus). Apesar de ser uma espécie cujo modo de vida é muito parecido ao do A. bisporus, são necessários estudos para o desenvolvimento de uma tecnologia de produção própria para o A. blazei e adequada às condições climáticas do Brasil e à realidade dos produtores brasileiros.

A tecnologia de produção do A. blazei, assim como do A. bisporus, envolve as seguintes etapas: preparo do substrato de cultivo (compostagem e pasteurização); inoculação; colonização do substrato; cobertura do substrato; produção e processamento.

Dentre as etapas de cultivo, a indução da frutificação merece destaque, uma vez que é considerada indispensável para o cultivo desse tipo de cogumelo e afeta diretamente a produtividade. A indução da frutificação é a etapa do cultivo em que se adiciona terra e/ou outros materiais sobre o substrato colonizado. $\mathrm{O}$ termo "camada

Parte da dissertação de Mestrado do primeiro autor apresentado à Universidade Federal de Lavras/UFLA.

${ }^{2}$ Mestre em Ciência dos Alimentos - Departamento de Ciência dos Alimentos/DCA - Universidade Federal de Lavras/UFLA - Cx. P. 3037 - 37200 - 000 Lavras, MG.

${ }^{3}$ Professor Adjunto do Departamento de Biologia/DBI - Universidade Federal de Lavras/UFLA - Cx. P. 3037 - 37200-000 - Lavras, MG.

${ }^{4}$ Professora Adjunta do Departamento de Ciência dos Alimentos/DCA - Universidade Federal de Lavras/UFLA - Cx. P. 3037 - $37200-000$ - Lavras, MG

${ }^{5}$ Estudante de Bacharelado em Ciências Biológicas da Universidade Federal de Lavras/UFLA - Cx. P. 3037 - $37200-000$ - Lavras, MG. 
de cobertura" é utilizado em referência ao material utilizado sobre o composto colonizado com o objetivo de induzir a frutificação (COLAUTO \& EIRA, 1998).

As funções básicas da camada de cobertura são: proteger o substrato colonizado contra a perda de umidade, promover microclima úmido para a formação e desenvolvimento dos primórdios, suporte físico (KURTZMAN, 1995), servir como reservatório de água para os cogumelos em crescimento, permitir trocas gasosas (KURTZMAN, 1995; WUEST \& BEYER, 1996), favorecer o desenvolvimento de microrganismos benéficos à frutificação (HAYES, 1978; REDDY \& PATRICK, 1990) e proteger o substrato de microrganismos competidores ou patogênicos. De acordo com a literatura pertinente, a espessura da camada de cobertura para o cultivo de Agaricus pode variar de 3 a $6 \mathrm{~cm}$ para substratos com profundidade de 15-20 cm (EDWARDS, 1978; KALBERER, 1983, 1985).

Diversos materiais têm sido utilizados como camada de cobertura ao longo do tempo, e Edwards (1978) mencionou que, após a década de 50 a turfa de musgo passou a ser utilizada como material de cobertura nos canteiros da Inglaterra, daí se expandindo para outros países da Europa e América do Norte.

O material utilizado como camada de cobertura deve apresentar características específicas como ter boa umidade e baixa capacidade para liberá-la (HAYES, 1981; VIJAY et al., 1987), ser livre de doenças e pragas (HAYES, 1978; VIJAY et al., 1987), apresentar porosidade suficiente para permitir trocas gasosas (HAYES, 1981; KURTZMAN, 1995), pH entre 6,5-8,0 (HAYES, 1978; VIJAY et al., 1987) e apresentar comunidade microbiana benéfica (CURTO \& FAVELI, 1972; HAYES, 1981; RAINEY et al., 1990).

Materiais alternativos foram testados como camada de cobertura, dentre eles: composto exaurido (HAYES, 1978), polpa de celulose (WUEST \& BEYER, 1996), fibras de coco (LABUSCHAGNE \& EIKER, 1995; PARDO et al., 2002), resíduos de pinheiro (PARDO et al., 2002), "rockwool" (lâ mineral), perlite e vermiculita (WUEST \& BEYER, 1996), dentre outros.

Hayes (1981) mencionou em seus estudos as dificuldades encontradas para determinar e padronizar um material de cobertura, considerando as complexas variações químicas, físicas e microbianas encontradas nos diferentes materiais. Segundo Colauto \& Eira (1998), até o momento, a turfa de musgo com pH ajustado com carbonato de cálcio ou calcário tem sido o material que melhor preenche os requisitos de uma boa camada de cobertura.
No Brasil, não existem ainda estudos específicos para o A. blazei sobre o uso de diferentes tipos de solos como camada de cobertura. De modo geral, para o cultivo desprotegido, utiliza-se a terra removida durante a preparação dos canteiros. Neste caso, não é feito nenhum tratamento de desinfestação da terra, ocorrendo apenas a retirada de raízes, pedras e outras sujidades e correção do pH para 7,0 com a utilização de calcário (BRAGA et al., 1998). Para o cultivo protegido em estufa ou câmara de cultivo, recomenda-se o uso de terra de barranco abaixo do horizonte A. Além disso, recomenda-se também que essa terra seja preferencialmente areno-argilosa ou que se utilize turfa de boa qualidade, quando a mesma é de fácil acesso e de custo baixo (COLAUTO, 2003; EIRA, 2003).

$O$ tratamento do material de cobertura deve ser realizado para eliminar possíveis pragas e doenças oriundos do local de coleta ou manuseio. No Brasil, a desinfestação do material usado pode ser feita de duas formas: com o tratamento a quente (vapor d'água) ou com reagentes químicos. No Brasil, a estrutura projetada para pasteurização de composto tem sido usada também com a finalidade de pasteurizar a terra de cobertura com vapor (PEIL et al., 1996).

Outro tratamento disponível consiste na adição de reagentes químicos e/ou fumigantes diretamente no material de cobertura. O método de desinfestação com solução de formol é uma alternativa com baixo custo, consistindo na irrigação de cada metro cúbico de terra com 20 litros de solução a 10\%. O material deve permanecer coberto durante período aproximado de 4-5 dias, e, para a sua utilização, deve ser descoberto e espalhado até a completa volatilização do formol (BRAGA et al., 1998).

Uma das preocupações com o tratamento de desinfestação da terra de cobertura é a possibilidade de eliminação de microrganismos importantes para o processo de frutificação. A presença de microrganismos no material de cobertura tem um papel importante na regulação e reprodução fúngica, uma vez que as interações microbianas ocorrem naturalmente no ambiente. Curto \& Faveli (1972) relataram que Eger (1962), foi o primeiro pesquisador a sugerir que a frutificação de cogumelos estava associada aos microrganismos. Posteriormente, diversos trabalhos foram conduzidos em condições laboratoriais e comprovaram a participação dos microrganismos associados com a frutificação de cogumelos comestíveis (CHO et al., 2003; CURTO \& FAVELI, 1972; HAYES, 1981; MILER et al., 1995; PARDO et al., 2002; RAINEY, 1991; RAINEY \& COLE, 1987; RAINEY et al., 1990; REDDY \& PATRICK, 1990). A espécie Pseudomonas putida é referida 
como estimuladora de crescimento e formação inicial de basidiomas em A. bisporus, proporcionando o estímulo necessário para desencadear a frutificação (FETT et al., 1995; GREWAL \& RAINEY, 1991; RAINEY, 1991; RAINEY \& COLE, 1987; RAINEY et al., 1990).

Por outro lado, nada se conhece acerca da importância da microbiota presente na camada de cobertura utilizada no cultivo do cogumelo A. blazei. Por isso, este trabalho teve como objetivos isolar, quantificar e identificar bactérias presentes em diferentes tipos de solos, bem como avaliar o efeito de diferentes tratamentos de desinfestação do material de cobertura sobre a sua comunidade bacteriana e sobre a produtividade do cogumelo.

\section{MATERIALE MÉTODOS}

\section{Obtenção do material de cobertura}

As amostras de material de cobertura (terra) foram obtidas nas proximidades de Lavras, MG, e conduzidas para a área experimental de cultivo de cogumelos comestíveis e medicinais situada nas dependências do Departamento de Biologia da UFLA. As três amostras de solos foram classificadas de acordo com Embrapa (2000), em Latossolo Vermelho distroférrico (LVdf), Latossolo Amarelo distrófico (LAdi) e Gleissolo Melânico (GSm). As amostras foram peneiradas em tela de arame galvanizado com malha de $1 \mathrm{~cm}$, para a retirada de raízes, pedras e vegetação nativa oriunda do local de coleta. Todas as amostras foram armazenadas em vasos de polietileno e posteriormente submetidas aos tratamentos.

\section{Cultivo de Agaricus blazei}

O composto utilizado para o cultivo de A. blazei foi adquirido previamente colonizado do Setor de Microbiologia do DBI/UFLA, e transferido para vasos de polietileno, onde cada vaso recebeu $5 \mathrm{~kg}$ de composto. A cada vaso foi adicionada uma camada de $5 \mathrm{~cm}$ de terra (de acordo com o tratamento).

\section{Desinfestação da camada de cobertura}

As amostras de camada de cobertura foram submetidas a dois tipos de tratamento: pasteurização com vapor d'água e tratamento com formol. O controle não recebeu nenhum tratamento, sendo apenas peneirado e acondicionado em vasos de polietileno.

As amostras desinfestadas com formol foram acondicionadas em vasos de polietileno (capacidade para $15 \mathrm{~kg}$ ) e a cada vaso foi adicionada solução de formol a $10 \%$, sendo 20 litros $/ \mathrm{m}^{3}$ de terra (BRAGA et al., 1998). Os vasos foram cobertos com sacos plásticos garantindo a vedação, permanecendo dessa forma por aproximadamente 5 dias. Para a utilização como camada de cobertura, foi removido o saco plástico e a terra foi espalhada até total volatilização do produto, ficando as amostras sem o odor característico da solução.

$\mathrm{Na}$ desinfestação com vapor d'água as três amostras de terra foram colocadas sobre uma tela (sombrite $75 \%$ ) no fundo de um pasteurizador de composto, ficando com aproximadamente 3-4 cm de altura, recebendo vapor d'água fluente durante um período aproximado de 6 horas. A temperatura no interior da câmara permaneceu entre $60^{\circ} \mathrm{C}$ e $65^{\circ} \mathrm{C}$.

Apenas para o trabalho de isolamento e quantificação de bactérias, amostras dos três tipos de solos foram submetidas à autoclavagem. Para isto, amostras de $1 \mathrm{~kg}$ de terra foram acondicionadas em sacos de polipropileno e autoclavadas a $121^{\circ} \mathrm{C}$ por 1 hora.

Alíquotas das três amostras de terra, submetidas aos três tratamentos, além do controle, foram coletadas assepticamente e transportadas para o Laboratório de Microbiologia do Departamento de Biologia da UFLA para as análises microbiológicas.

\section{Quantificação da comunidade bacteriana nos diferentes tipos de solo}

Para a análise microbiológica, $10 \mathrm{~g}$ das diferentes amostras foram transferidas para frascos Erlenmeyer contendo $90 \mathrm{~mL}$ de água peptonada $0,1 \%$ estéril. Cada amostra foi agitada a $200 \mathrm{rpm} / 30$ minutos. Para a contagem de colônias, foi utilizada a técnica de plaqueamento por microgota (ROMEIRO, 2001), das diluições decimais seriadas em meio de cultivo ágar nutriente (AN) (em g/L: extrato de carne, 3; peptona bacteriológica, 5; $\mathrm{NaCl}$, 3; ágar, 13) e PIA ("Pseudomonas Isolation Agar"-DIFCO) (em g/ L: peptona bacteriológica, 20; cloreto de magnésio, 1,4; sulfato de potássio, 10; Irgasan ${ }^{\circledR} 0,025$; ágar bacteriológico, 13,6). As placas foram incubadas a $25^{\circ} \mathrm{C} \pm$ $1^{\circ} \mathrm{C}$, durante 24 horas. Após incubação, foram selecionadas as placas que continham entre 3-30 colônias. O número de colônias contadas foi multiplicado pela recíproca da diluição e o resultado expresso como unidades formadoras de colônias (UFC).

\section{Isolamento e identificação de bactérias da camada de cobertura}

Para a seleção de isolados de acordo com o morfotipo das colônias, foi utilizado o cálculo da raiz total destes, que foram transferidos para tubos de ágar inclinado 
com o meio original e incubado em temperatura ambiente até o crescimento das colônias. Os isolados foram purificados utilizando-se a técnica de estrias compostas em meio AN e confirmada sua pureza com testes de coloração de Gram. As cepas de bactérias Gram-negativas foram identificadas por meio dos "kits" bioquímicos Bactray I, II e III.

Além do isolamento de bactérias nos diferentes tipos de terra submetidos aos dois tratamentos, foi realizado o isolamento de bactérias na camada de cobertura desde a colocação da terra sobre o composto colonizado até o início da frutificação. Para essa etapa, foi selecionado o Latossolo Amarelo distrófico (LAdi) desinfestado por vapor d'água. Foram utilizados 10 vasos com $5 \mathrm{~kg}$ de composto/ vaso e uma camada de $5 \mathrm{~cm}$ de cobertura. Foram retiradas aleatoriamente alíquotas de terra desses vasos, a $1 \mathrm{~cm}$ de profundidade, durante o período de 1, 7, 14, 21, 28 e 32 dias, até início da frutificação, para avaliar o número de bactérias presentes na terra durante esse período e identificá-los.

\section{Produtividade de A. blazei em Latossolo Amarelo distrófico}

As amostras do solo LAdi, submetidas aos tratamentos com formol e vapor d'água, além do controle (sem tratamento), foram utilizadas como camada de cobertura, para avaliação da produtividade em cada tratamento.

\section{RESULTADOS E DISCUSSÃO}

\section{Quantificação da comunidade bacteriana presente na camada de cobertura}

$\mathrm{Na}$ Tabela 1, encontra-se a contagem total de bactérias presentes em três diferentes terras utilizadas como camada de cobertura, com resultados expressos em $\mathrm{UFC} \mathrm{g}^{-1}$. Os métodos de desinfestação foram analisados e correlacionados com os tipos de solos utilizados como camada de cobertura. $\mathrm{O}$ tratamento com formol apresentou redução mais expressiva no número de microrganismos, não apresentando diferenças significativas entre o Latossolo Vermelho distroférrico (LVdf) e o Latossolo Amarelo distrófico (LAdi). No solo hidromórfico (Gleissolo Melânico - GSm), os tratamentos não foram eficientes na redução da comunidade microbiana, sendo quantificados valores de 3,57 a 12,4 x $10^{6} \mathrm{UFC} \mathrm{g}^{-1}$. Tal fato deve-se, provavelmente, às propriedades estruturais da amostra, a qual é proveniente de uma área de várzea, contendo grande quantidade de matéria orgânica, umidade excessiva e alta capacidade de retenção de água.

Pardo et al. (2002) obtiveram valores médios para contagem total de bactérias de $3,5 \times 10^{5}$ a $2,1 \times 10^{7} \mathrm{UFC} \mathrm{g}^{-1}$, trabalhando com diferentes tipos de camada de cobertura utilizadas no cultivo de A. bisporus na Espanha. Foram testados solos e uma mistura binária de $80 \%$ de solo e $20 \%$ de materiais alternativos, como turfa, turfa negra, resíduos da indústria madeireira, fibra de coco e resíduos de uva. Os resultados referentes à contagem média de bactérias ao utilizar somente terra como material de cobertura estão compreendidos entre $10^{5}$ e $10^{6} \mathrm{UFC} \mathrm{g}^{-1}$, determinados no momento da colocação da camada de cobertura sobre o composto colonizado. Colauto \& Eira (1998), também ao analisarem diferentes materiais usados como camada de cobertura para $A$. bisporus no Brasil, encontraram elevadas populações de bactérias em geral $\left(10^{7} \mathrm{UFC} \mathrm{g}^{-1}\right)$ e também de Pseudomonas spp $\left(10^{6} \mathrm{UFC} \mathrm{g}^{-1}\right)$.

A contagem total de bactérias (Figura 1) e de Gramnegativos (Figura 2) foi determinada durante 32 dias após a etapa de cobertura do composto colonizado. Os dados estão expressos em tendência polinomial, com coeficiente de determinação $\mathrm{R}^{2}$ de $96 \%$ para contagem total de bactérias e $88 \%$ para bactérias Gram-negativas.

TABELA 1 - Contagem total de bactérias presentes nas três diferentes terras submetidas aos tratamentos de desinfestação da camada de cobertura, expressos em UFC g- ${ }^{1}$.

\begin{tabular}{|c|c|c|c|c|c|}
\hline \multirow[b]{2}{*}{ Tratamento } & \multicolumn{3}{|c|}{ Tipos de solos ${ }^{1}$} & \multirow{2}{*}{\multicolumn{2}{|c|}{ Média* }} \\
\hline & LAdi & GSm & LVdf & & \\
\hline Autoclavagem & $\mathrm{cA}$ & $0 \quad \mathrm{cA}$ & $\begin{array}{ll}0 & \mathrm{dA}\end{array}$ & 0 & $\mathrm{c}$ \\
\hline Formol & $0,05 \times 10^{6} \quad b B$ & $12,4 \times 10^{6}$ aA & $0,03 \times 10^{6} \mathrm{cB}$ & $4,15 \times 10^{6}$ & $\mathrm{~b}$ \\
\hline Vapor & $3,72 \times 10^{6}$ aA & $3,57 \times 10^{6}$ bA & $0,23 \times 10^{6} \mathrm{bB}$ & $2,64 \times 10^{6}$ & $\mathrm{a}$ \\
\hline Controle & $4,13 \times 10^{6}$ aA & $4,50 \times 10^{6}$ bA & $0,80 \times 10^{6} \mathrm{aB}$ & $3,00 \times 10^{6}$ & $\mathrm{a}$ \\
\hline Média $^{2}$ & $1,98 \times 10^{6} \quad B$ & $5,12 \times 10^{6} \quad A$ & $0,26 \times 10^{5} \quad \mathrm{C}$ & & \\
\hline
\end{tabular}

1- LAdi= Latossolo Amarelo distrófico, GSm= Gleissolo Melânico, LVdf= Latossolo Vermelho distroférrico.

2- Médias seguidas da mesma letra não diferem estatisticamente entre si, pelo Teste de Tukey, a 5\% de probabilidade. Letras minúsculas comparam as médias em cada coluna e as letras maiúsculas comparam as médias em cada linha. 


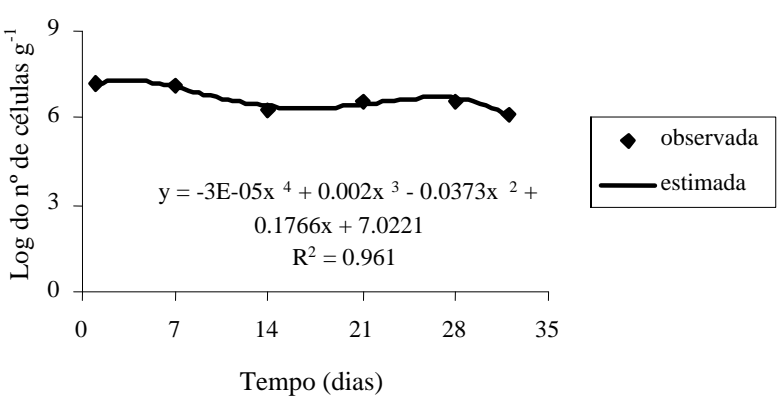

FIGURA 1 - Contagem total de bactérias presentes a $1 \mathrm{~cm}$ de profundidade no Latossolo Amarelo distrófico desinfestado por vapor d'água no período de 1 a 32 dias após a indução da frutificação.

A contagem total de bactérias revelou a diminuição da comunidade bacteriana inicial até o 14ํ dia. Após esse período, verificou-se um ligeiro aumento no crescimento da comunidade. Em trabalhos com A. bisporus, Reddy \& Patrick (1990) observaram que a comunidade bacteriana manteve altos índices, associada à camada de cobertura, durante as primeiras semanas. Segundo os mesmos autores, foi observada acentuada atividade bacteriana em dois picos na camada de cobertura, uma a aproximadamente 14 dias e a outra com 42 dias após a aplicação da cobertura do composto colonizado com $A$. bisporus.

No presente trabalho, a diminuição da comunidade bacteriana no Latossolo Amarelo distrófico até o 14ํㅡㄹ dia pode ser explicada pelo fato da superfície sofrer maiores variações de umidade e temperatura. Após 14 dias, a terra de cobertura já está praticamente colonizada até a superfície pelo micélio do A. blazei; portanto, é possível que a estabilização da comunidade bacteriana esteja associada à colonização da terra pelo fungo. De forma semelhante, observou-se uma queda da comunidade de bactérias Gram-negativas nos primeiros dias de cultivo, porém, após 14 dias, verificou-se não apenas uma estabilização da comunidade, mas também uma recuperação do número observado originalmente nesse tipo de solo. Esses resultados sugerem um maior efeito positivo da colonização da terra pelo micélio sobre as bactérias Gram-negativas.

Em trabalho com A. bisporus, Pardo et al. (2002) também observaram aumento na comunidade bacteriana na contagem total e contagem de bactérias Gram-negativas após o primeiro fluxo de frutificação, a qual manteve-se elevada durante os sucessivos fluxos.

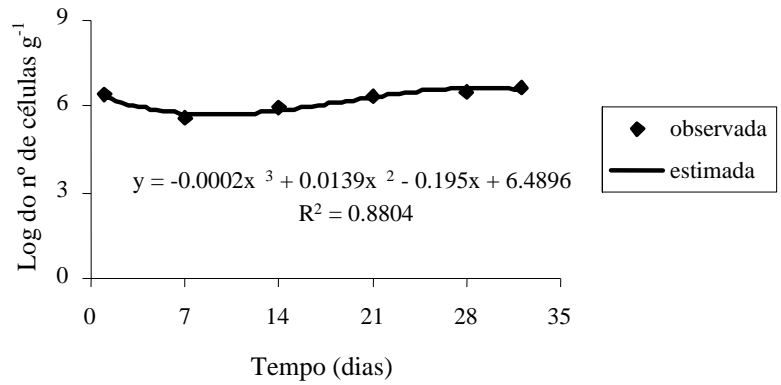

FIGURA 2 - Contagem de bactérias Gram-negativas presentes a $1 \mathrm{~cm}$ de profundidade no Latossolo Amarelo distrófico desinfestado por vapor d'água, no período de 1 a 32 dias após a indução da frutificação.

Diversos autores relataram que bactérias do gênero Pseudomonas sp predominam no cultivo de A. bisporus, associadas ao composto e aos diferentes materiais utilizados como cobertura (COLAUTO \& EIRA, 1998; MILLER et al., 1995;PARDO et al., 2002; REDDY \& PATRICK, 1990). Colauto \& Eira (1998) observaram densa população de Pseudomonas sp no material de cobertura durante a fase de produção. Tal fato pode ser influenciado pela quimiotaxia dessas bactérias, que respondem ao gradiente de nutrientes excretados pelo micélio (GREWAL \& RAINEY, 1991; MASAPHY et al., 1987; MILLER et al., 1995).

Miller et al. (1995) consideraram a influência de dois fatores no aumento do número de bactérias pertencentes ao gênero Pseudomonas sp, em relação ao total de bactérias após a colocação da cobertura sobre o composto colonizado. $\mathrm{O}$ primeiro fato refere-se ao ambiente fornecido pela camada de cobertura, a qual possui escassez de nutrientes, e o segundo fator é inerente à produção de metabólitos pelo fungo que, possivelmente, cria um gradiente nutricional ao qual as bactérias podem responder por quimiotaxia. A capacidade de Pseudomonas sp moverse em direção aos nutrientes confere vantagem sobre aquelas com menor motilidade ou não quimiostáteis (MILLER et al., 1995). Grewal \& Rainey (1991) demonstraram a migração de $P$. putida e $P$. tolaasii em direção aos exsudados do micélio de $A$. bisporus, reforçando a idéia de que o mesmo fato pode ocorrer no ambiente de cobertura do composto.

\section{Identificação de bactérias isoladas do material de cobertura}

Os microrganismos identificados nos diferentes tratamentos e terras, neste trabalho, estão listados nas 
Tabela 2 a 5, demonstrando diferentes membros do gênero Pseudomonas sp e outras espécies de bactérias. A bactéria $P$. putida tem sido relatada como espécie presente no processo de indução de frutificação (CURTO \& FAVELLI, 1972; HUME \& HAYES, 1972; RAINEY \& COLE, 1987), entretanto, não foi possível identificá-la nas amostragens. No entanto, ainda não se pode afirmar que essa espécie não esteja presente, uma vez que somente parte dos microrganismos isolados foi identificada.

Nas Tabelas 2 e 3, mostram-se as espécies de bactérias isoladas das terras sem tratamento e desinfestadas com formol, respectivamente, enquanto a Tabela 4 refere-se às espécies isoladas das terras desinfestadas com vapor d'água.
De maneira geral, os microrganismos identificados em função dos tratamentos de desinfestação da terra, compreendem bactérias dos gêneros Salmonella, Shigella, Achromobacter, Serratia, Enterobacter, Flavobacterium, Kluyvera, Tatumella e Pseudomonas, dentre outros.

Os resultados de identificação mostraram, por um lado, que os métodos de desinfestação não eliminaram espécies de bactérias potencialmente benéficas para a frutificação. Porém, outra observação muito importante foi que esses tratamentos também não eliminaram bactérias potencialmente patogênicas ao homem. Esses resultados mostram a necessidade de monitoramento microbiológico dos cogumelos pós-colheita e de cuidadoso procedimento de colheita, lavagem e desidratação dos mesmos.

TABELA 2 - Bactérias Gram-negativas isoladas de três amostras de solos utilizadas como camada de cobertura, sem tratamento de desinfestação.

\begin{tabular}{lll}
\hline \multicolumn{1}{c}{ Gleissolo Melânico } & \multicolumn{1}{c}{ Latossolo Amarelo distrófico } & Latossolo Vermelho distroférrico \\
\hline Serratia odorifera & E. agglomerans & Escherichia coli \\
Shigella flexner & F. meningosepticum & P. aerogenes \\
Enterobacter agglomerans & Pseudomonas vesicularis & F. meningosepticum \\
Flavobacterium odoratum & Pseudomonas putrefaciens & \\
F. meningosepticum & Flavobacterium II & \\
Pseudomonas fluorescens & & \\
\hline
\end{tabular}

TABELA 3 - Bactérias Gram-negativas isoladas de três amostras de solos utilizadas como camada de cobertura, desinfestadas com formol.

\begin{tabular}{lll}
\hline \multicolumn{1}{c}{ Gleissolo Melânico } & \multicolumn{1}{c}{ Latossolo Amarelo distrófico } & Latossolo Vermelho distroférrico \\
\hline Salmonella enteritidis & Flavobacterium II & Escherichia coli \\
Pseudomonas putrefaciens & Pseudomonas fluorescens & \\
Pasteurella multocida & & \\
Tatumella ptyseos & \\
Enterobacter agglomerans & \\
Flavobacterium II & & \\
\hline
\end{tabular}

TABELA 4 - Bactérias Gram-negativas isoladas de três amostras de solos utilizadas como camada de cobertura, desinfestadas com vapor d'água.

\begin{tabular}{lll}
\hline \multicolumn{1}{c}{ Gleissolo Melânico } & \multicolumn{1}{c}{ Latossolo Amarelo distrófico } & \multicolumn{1}{c}{ Latossolo Vermelho distroférrico } \\
\hline Serratia odorifera & Serratia odorifera & Shigella dysenteriae \\
Shigella boydii & Pseudomonas cepacia & F. meningosepticum \\
Yersinia enterocolitica & Salmonella cholerae-suis & P. cepacia \\
P. fluorescens & Aeromonas hydrophila & P. paucimobilis \\
Achromobacter sp & F. meningosepticum & \\
& Escherichia coli & \\
& Enterobacter agglomerans & \\
& Pasteurella haemolyticus & \\
& Pseudomonas fluorescens & \\
\hline
\end{tabular}


Na Tabela 5 estão descritas as espécies de bactérias isoladas da camada de cobertura desde o momento da adição de terra sobre o composto colonizado (cobertura) até o 32o dia. É importante notar que o gênero Pseudomonas esteve presente desde o $1^{\mathrm{o}}$ até o $32^{\circ}$ dia, o mesmo ocorrendo com espécies potencialmente patogênicas.

Cho et al. (2003) isolaram e identificaram 45 bactérias aderidas ao micélio de $P$. ostreatus, pertencentes a 17 gêneros diferentes. Dentre os isolados encontram-se Enterobacter, Salmonella, Pseudomonas, Kluyvera e a espécie $P$. putida. Os quatro gêneros citados acima também foram identificados nas terras utilizadas como material de cobertura no cultivo de A. blazei.

\section{Produtividade de $A$. blazei}

Os valores obtidos referentes à produtividade de A. blazei nos diferentes métodos de desinfestação de terra estão demonstrados na Tabela 6. Os resultados de produtividade referem-se a apenas 2 meses de frutificação contados a partir da adição da camada de cobertura sobre o composto colonizado. Portanto, os resultados de produção são apenas parciais, porque normalmente o ciclo de produção estende-se por, pelo menos, 3 meses. Considerando os valores de produção de cogumelos desidratados, a produtividade variou de 0,85 a $1,0 \%$, em função dos tratamentos de desinfestação, porém, essas diferenças não foram significativas. Esses resultados sugerem, para as condições testadas, que a desinfestação da terra de cobertura não comprometeu a frutificação do cogumelo A. blazei. Não foi avaliada a terra autoclavada, a princípio pelo fato deste método não ser uma alternativa viável economicamente. No entanto, considerando que não houve efeito negativo dos tratamentos com vapor ou formol, será importante em um estudo futuro a avaliação do efeito da autoclavagem da terra de cobertura sobre a produtividade do cogumelo A. blazei, com o objetivo de se averiguar se a comunidade microbiana presente é necessária ou não para a frutificação desse cogumelo.

Com relação à produtividade de A. blazei, Eira (2003) mencionou que podem ser obtidos índices de 3 a $25 \%$ em base úmida. $\mathrm{O}$ percentual de conversão do substrato em biomassa fúngica é denominado de eficiência biológica

TABELA 5 - Bactérias Gram-negativas isoladas do Latossolo Amarelo distrófico (LAdi) desinfestado com vapor d'água, durante período de 32 dias após indução da frutifica.

\begin{tabular}{|c|c|c|}
\hline Dias de amostragem & & anismos* \\
\hline \multirow[t]{2}{*}{$1^{\circ} \mathrm{dia}$} & Salmonella enteritidis & Shigella boydii \\
\hline & Pasteurella multocida & Pseudomonas fluorescens \\
\hline \multirow[t]{2}{*}{$7^{\circ}$ dia } & Escherichia coli & Pseudomonas fluorescens (2) \\
\hline & Flavobacterium II & \\
\hline \multirow[t]{3}{*}{$14^{\circ}$ dia } & Pasteurella multocida & Salmonella enteritidis \\
\hline & F. meningosepticum & Pseudomonas cepacia \\
\hline & Escherichia coli & \\
\hline $21^{\circ}$ dia & P. fluorescens (2) & \\
\hline $28^{\circ} \mathrm{dia}$ & Salmonella enteritidis & Shigella flexner (2) \\
\hline & Yersinia enterocolitica & \\
\hline $32^{\circ}$ dia & Pseudomonas cepacia & Pseudomonas aeruginosa (2) \\
\hline
\end{tabular}

* O número entre parênteses indica a quantidade de microrganismo de mesma espécie.

TABELA 6 - Produtividade* de A. blazei em função dos três métodos de desinfestação do material de cobertura, utilizando Latossolo Amarelo distrófico (LAdi), oriundo de área de pastagem.

\begin{tabular}{lccc}
\hline \multicolumn{1}{c}{ Desinfestação } & $\begin{array}{c}\text { Cogumelo fresco } \\
\text { (g/ 5 kg composto) }\end{array}$ & $\begin{array}{c}\text { Produtividade (\%) cogumelo } \\
\text { fresco }\end{array}$ & $\begin{array}{c}\text { Produtividade (\%) cogumelo } \\
\text { seco }\end{array}$ \\
\hline Formol & 307 & $6,14 \%$ & $0,92 \%$ \\
Vapor d'água & 285 & $5,70 \%$ & $0,85 \%$ \\
Sem tratamento & 391 & $7,82 \%$ & $1,00 \%$ \\
\hline
\end{tabular}

* valores médios de 2 meses de frutificação. 
(EB). No cultivo de A. blazei, a EB ainda é muito baixa quando comparada à do $A$. bisporus na Europa, com valores de $105 \%$ (EIRA, 2003). No Brasil, considera-se que a produtividade de $A$. blazei deve ser de, pelo menos, $1 \%$ para que o cultivo seja viável economicamente, considerando o cogumelo seco. No presente estudo, com apenas 2 meses de cultivo, foram alcançados índices em torno de $1 \%$ de produtividade do A. blazei.

\section{CONCLUSÕES}

A desinfestação da terra de cobertura com formol apresentou maior redução no número total de bactérias em relação ao tratamento com vapor.

A recuperação da população de bactérias Gramnegativas 32 dias após a cobertura do composto colonizado foi maior em relação ao número total de bactérias.

Os tratamentos com formol ou vapor d'água não eliminaram bactérias potencialmente benéficas do gênero Pseudomonas, mas também não eliminaram bactérias potencialmente patogênicas, tais como Salmonella, Shigella, Serratia, Enterobacter, Tatumella, dentre outras.

Os tratamentos com formol ou vapor d'água não afetaram negativamente a produtividade do cogumelo $A$. blazei nas condições testadas.

\section{REFERÊNCIAS BIBLIOGRÁFICAS}

BRAGA, G. C.; EIRA, A. F. Efeitos da camada de cobertura, da massa do substrato e do ambiente de cultivo, na produtividade de Agaricus blazei Murril. Energia na Agricultura, Botucatu, v. 14, n. 1, p. 39-51, 1999.

BRAGA, G. C.; EIRA, A. F.; CELSO, P. G.; COLAUTO, N. B. Manual do cultivo de Agaricus blazei Murr. "Cogumelodo-sol". Botucatu: Fundação de Estudos e Pesquisas Agrícolas e Florestais, 1998. 44 p.

CHO, Y. S.; KIM, J. S.; CROWLEY, D. E.; CHO, B. G. Growth promotion of the edible fungus Pleurotus ostreatus by fluorescent pseudomonads. FEMS Microbiology Letters, Amsterdam, v. 218, n. 2, p. 271-276, 2003.

COLAUTO, N. B. Cultivo de cogumelos utilizando diferentes camadas de cobertura. In: SIMPÓSIO INTERNACIONAL SOBRE COGUMELOS NA ALIMENTAÇÃO, SAÚDE, TECNOLOGIA E MEIO AMBIENTE NO BRASIL, 1., 2003, Brasília, DF. Anais... Brasília, DF: [s.n.], 2003. p. 77-78.
COLAUTO, N. B.; EIRA, A. F. Avaliação quantitativa da comunidade bacteriana na camada de cobertura de Agaricus bisporus. Energia na Agricultura, Botucatu, v. 13, n. 2, p. 15-26, 1998.

CURTO, S.; FAVELLI, F. Stimulative effect of certain microorganisms (bacteria, yeasts, microalgae) upon fruit-body formation of Agaricus bisporus (Lange) Sing. Mushroom Science, [S.1.], v. 7, n. 1, p. 67-74, 1972.

EDWARDS, R. L. Cultivation in Western Countries: growing in houses. In: The biology and cultivation of edible mushrooms. New York: Academic, 1978. cap. 12, p. 300-336.

EGER, G. The "Halbschalentest", a simple method for testing casing materials. Mushroom Growers Association Bull, [S.l.], v. 148, p. 159-168, 1962.

EIRA, A. F. Cultivo do cogumelo medicinal Agaricus blazei (Murril) ss. Heinemann ou Agaricus brasilienseis (Wasser et al.). Viçosa: Aprenda Fácil, 2003. 398 p.

EMPRESA BRASILEIRA DE PESQUISA AGROPECUÁRIA. Sistema brasileiro de classificação de solos. Brasília, DF, 2000. 412 p.

FETT, W. F.; WELLS, J. M.; CESCUTTI, P.; WIJEY, C. Identification of exopolysaccharides produced by fluorescent Pseudomonads associated with commercial mushroom (Agaricus bisporus) production. Applied and Environmental Microbiology, Washington, v. 61, n. 2, p. 513-517, 1995.

GREWAL, S. I. S.; RAINEY, P. B. Phenotypic variation of Pseudomonas putida and $P$. tolaasii affects the chemotactic response to Agaricus bisporus mycelial exudate. Journal of General Microbiology, London, v. 137, n. 12, p. 2761-2768, 1991.

HAYES, W. A. Nutrition, substrates and principles of diseases control. In: The biology and cultivation of edible mushrooms. New York: Academic, 1978. cap. 9, p. 220-237.

HAYES, W. A. Interrelated studies of physical, chemical and biological factors in casing soils and relationships with productivity in comercial culture of $A$. bisporus Lange (Pilat). In: INTERNATIONAL SCIENTIFIC CONGRESS ON THE CULTIVATION OF EDIBLE FUNGI: MUSHROOM SCIENCE, 1981, Australia. Proceeding... Melbourne: Balkena, 1981. v. 11, p. 103-129. 
HUME, D. P.; HAYES, W. A. The production of fruit-body primordia in Agaricus bisporus (Lange) Sing on agar media. In: INTERNATIONAL CONGRESS OF MUSHROOM SCIENCE, 8., 1971, Lonon. Proceedings... London: Balkena, 1972. p. 527-532.

KALBERER, P. P. Influence of the depth of the casing layer and the harvesting time on changes of the water content of the casing layer and the substrate caused by the first flush of mushrooms. Scientia Horticulturae, Amsterdam, v. 21, n. 1, p. 9-18, 1983.

KALBERER, P. P. Influence of the depth of the casing layer on the water extracton from casing soil and substrate by the sporophores, on the yield and on the dry matter content of the fruit bodies of the first three flushes of the cultivated mushrom, Agaricus bisporus. Scientia Horticulturae, Amsterdam, v. 27, n. 1/2, p. 33-43, 1985.

KAWAGISHI, H.; KANAO, T.; INAGAKI, R.; MIZUNO, T.; SHIMURA, K.; ITO, H.; HAGIWARA, T.; NAKAMURA, T. Formolysis of a potent antitumor (1-6)b-D-glucan-protein complex from Agaricus blazei fruiting bodies and antitumor activity of the resulting products. Carbohydrates Polymers, [S.1.], v. 12, n. 4, p. 393-403, 1990.

KURTZMAN, R. H. Agaricus bisporus (Lge) Imb.casing layer II: porosity, the most important character. International Journal of Mushroom Science, [S.1.], v. 1, n. 1, p. 11-17, 1995.

LABUSCHAGNE, P.; EICKER, A. Casing mediums for Agaricus bisporus cultivation in South Africa: a preliminary report. In: INTERNATIONAL CONGRESS OF THE SCIENCE AND CULTIVATION OF EDIBLE FUNGI, 14., 1995, Balkema, Roterdã. Proceedings... Balkema: [s.n.], 1995. p. 339-344.

MASAPHY, S.; LEVANON, D.; TCHELET, R.; HENIS, Y. Scanning electron microscope studies of interactions between Agaricus bisporus (Lang) Sing hyphae and bacteria in casing soil. Applied and Environmental Microbiology, Washington, v. 53, n. 5, p. 1132-1137, 1987.

MILLER, N.; GILLESPIE, J. B.; DOYLE, O. P. E. The involvement of microbiological components of pet based casing materials in fructification of Agaricus bisporus. In: INTERNATIONAL CONGRESS OF THE SCIENCE AND CULTIVATION OF EDIBLE FUNG, 14., 1995, Balkema, Roterdã. Proceedings... Balkema: [s.n.], 1995. p. 313-321.

MIZUNO, T.; HAGIWARA, T.; NAKAMURA, T.; ITO, H.; SHIMURA, K.; SUMIYA, T.; ASAKURA, A. Antitumor activity and some properties of water-insoluble heteroglycans from "Himematsutake," the fruting body of Agaricus blazei Murril. Agricultural and Biological Chemistry, [S.1.], v. 54, n. 11, p. 2889-2896, 1990a.

MIZUNO, T.; INAGAKI, R.; KANNO, T.; HAGIWARA, T.; NAKAMURA, T.; ITO, H.; SHIMURA, K.; SUMIYA, T.; ASAKURA, A. Antitumor activity and some properties of water-soluble polysaccharides from "Himematsutake," the fruiting body of Agaricus blazei Murril. Agricultural and Biological Chemistry, [S.1.], v. 54, n. 11, p. 2897-2906, $1990 \mathrm{~b}$.

PARDO, A.; DE-JUAN, J. A.; PARDO, J. E. Bacterial activity in different types of casing during mushroom cultivation Agaricus bisporus (Lange) Imbach. Acta Alimentaria, [S.1.], v. 31, n. 4, p. 327-342, 2002

PEIL, R. M.; ROSSETO, E. A.; PIEROBOM, C. R.; ROCHA, M. T. Desinfestação de composto para cultivo de cogumelo Agaricus bisporus (Lange) Imbach. Revista Brasileira de Agrociência, [S.1.], v. 2, n. 3, p. 159-164, 1996.

RAINEY, P. B. Effect of Pseudomonas putida on hyphal growth of Agaricus bisporus. Mycological Research, Cambridge, v. 95, n. 6, p. 699-704, 1991.

RAINEY, P. B.; COLE, A. L. J. Evidence for the involvement of plasmids in sporophore initiation and development in Agaricus bisporus. In: INTERNATIONAL SYMPOSIUM OF SCIENTIFIC AND TECHNICAL ASPECTS OF CULTIVATING EDIBLE FUNGI; DEVELOPMENT IN CROP SCIENCE, 10., 1986, Amsterdam. Proceedings... Amsterdam: University Park, 1987. p. 235-248.

RAINEY, P. B.; COLE, A. L. J.; FERMOR, T. R.; WOOD, D. A. A model system for examining involvement of bacteria in basidiome initiation of Agaricus bisporus. Mycological Research, Cambridge, v. 94, n. 2, p. 191-195, 1990. 
REDDY, M. S.; PATRICK, Z. A. Effect of bacteria associated with mushroom compost and casing materials on basidiomata fomation in Agaricus bisporus. Canadian Journal of Plant Pathology, [S.1.], v. 12, n. 3, p. 236-242, 1990.

ROMEIRO, R. S. Métodos em bacteriologia de plantas. Viçosa: UFV, 2001. 279 p.
VIJAY, B.; SAXENA, S.; SOHI, H. S. Studies on new casing media for Agaricus bisporus (Lange) Sing. The Mushroom Journal, [S.1.], n. 178, p. 313-315, 1987.

WUEST, P.; BEYER, D. M. Manufactured and recycled materials used as casing in (Agaricus bisporus) mushroom production. In: . Mushroom biology and mushroom products. [S.1.: s.n.], 1996. p. 241-250. 